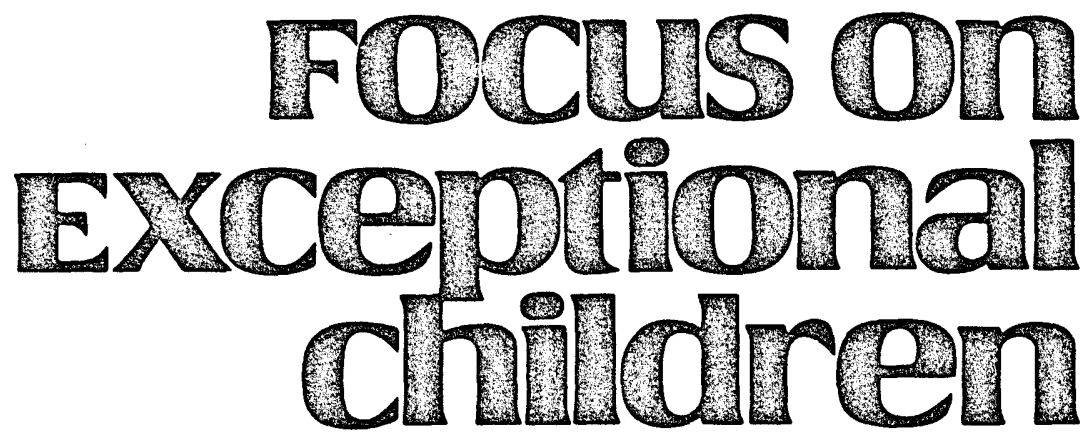

\title{
Curriculum-Based Measurement and Problem-Solving Assessment: Basic Procedures and Outcomes
}

\author{
Mark R. Shinn and Dawn D. Hubbard
}

More than 15 years after the passage of the Education for All Handicapped Children Act (EAHCA), assessment and testing practices with students who have mild handicaps remain essentially unchanged. Testing is characterized by a high reliance on commercially available, published norm-refereficed tests (PNTs) of aptitude, achievement, and specific "abilities" (Reschly, Genshaft, \& Binder, 1987). The lack of change is disturbing to many educators, as historically these practices have generated considerable controversy and little evidence of efficacy (Bersoff, 1973).

Most of the controversy has centered on appropriateness of PNTs to identify students as learning disabled (LD), educably mentally retarded (EMR) or low achieving (Gerber \& Semmel, 1984; Heller, Holtzman, \& Messick, 1982; Ysseldyke, Algozzine, Shinn, \& McGue, 1982; Ysseldyke \& Thurlow, 1984). Their accuracy and efficacy to diagnose students differentially among disability categories has been the subject of many research articles and much special education placement litigation (e.g., Reschly, Kicklighter, \& McKee, 1988c). The focus on PNTs in identification has obscured a more important question, however. Can the data derived from current testing practices be used to: (a) develop more effective interventions, and (b) evaluate the effectiveness of any specific intervention implemented (Deno, 1986; 1989)? Measurement experts summarizing litigation (e.g., Reschly, Kicklighter, \& McKee, 1988a; 1988b; 1988c) concluded that the link to intervention planning and evaluation is what will form the basis for promoting assessment practices as useful.

A number of resources detail why information derived from PNTs is difficult to link to intervention planning and intervention evaluation (e.g., Marston, 1989; Shinn, Nolet, \& Knutson, 1990). Stated briefly, to be useful for planning instructional interventions, a test must provide information about what skills, task preskills, or problem-solving algorithms a student does and does not demonstrate that are essential for success in the curriculum the student is expected to learn (Howell \& Morehead, 1987). Key features of tests to be used for these purposes include high content validity, enough items to reliably detect error and success patterns, and response formats that rely on production-type responses (e.g., writing answers to math problems). To be useful for evaluating effectiveness of the intervention, a test must be capable of being used to write long-term (i.e., annual) goals and be used on a

Dr. Shinn is with the School Psychology Program, Division of Special Education and Rehabilitation, University of Oregon, Eugene. Dawn Hubbard is a doctoral student in the School Psychology Program at the University of Oregon, Eugene. 
repeated and frequent basis so that effective interventions are maintained and ineffective interventions are modified.

Key features again include content validity, a sufficient number of items drawn from the curriculum, and production-type responses. Content validity ensures that decisions are made on the basis of what students are expected to learn. A sufficient number of items is necessary so that the test is "sensitive" to change. Production-type responses allow for a careful analysis of a student's pattern of successes and errors that facilitates modifications of the current intervention, if necessary (Howell \& Morehead, 1987).

As detailed in Figure 1, PNTs, at best, can be used to describe the severity of an academic problem relative to the academic performance of what is typically a nationally normed sample. The utility of this use of PNTs is most defensible when the test has high content validity. Even with PNTs that have high content validity, however, information for intervention planning and evaluation is lacking or must be extrapolated or collected via devices and methods in addition to or after a special education certification/eligibility decision has been made.

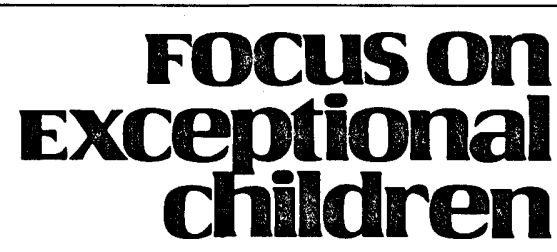

ISSN 0015-511X

FOCUS ON EXCEPTIONAL CHILDREN (USPS 203-360) is published monthly except June, July, and August as a service to teachers, special educators, curriculum specialists, administrators, and those concerned with the special education of exceptional children. This publication is annotated and indexed by the ERIC Clearinghouse on Handicapped and Gifted Children for publication in the monthly Current Index to Journals in Education (CIJE) and the quarterly index, Exceptional Children Education Resources (ECER). It is also available in microfilm from Xerox University Microfilms, Ann Arbor, MI. Subscription rates: Individual, \$27 per year; institutions, $\$ 36$ per year. Copyright (C) 1992, Love Publishing Company. All rights reserved. Reproduction in whole or part without written permission is prohibited. Printed in the United States of America. Second class postage is paid at Denver, Colorado. POSTMASTER: Send address changes to:

Love Publishing Company

Executive and Editorial Office

1777 South Bellaire Street

Denver, Colorado 80222

Telephone (303) 757-2579

Edward L. Meyen

University of Kansas

\begin{abstract}
Glenn A. Vergason Georgia State University
\end{abstract}

Richard J. Whelan

University of Kansas Medical Center

Stanley F. Love

Publisher
Holly T. Rumpler Senior Editor

\section{CURRICULUM-BASED ASSESSMENT AS A VIABLE ALTERNATIVE}

One of the most frequently proposed solutions to using PNTs is curriculum-based assessment (CBA). CBA has been promoted because of its purported linkage of assessment and intervention (Reschly et al., 1988c) and because of its emphasis on data for intervention planning (Tucker, 1985). Unfortunately, CBA is not one set of unified testing strategies or procedures. Instead, CBA approaches range from testing procedures that resemble teacher-made criterion-referenced tests (Criterion-referenced curriculum-based assessment, C-R CBA, Blankenship, 1985) to procedures designed to determine a student's frustrational, instructional, and independent academic levels (Curriculum-Based Assessment for Instructional Design, C-BAID, Gickling \& Thompson, 1985), and to a set of short-duration fluency measures of reading, written expression, spelling, and mathematics computation (CurriculumBased Measurement, CBM, Deno, 1985, 1986; Shinn, 1989a).
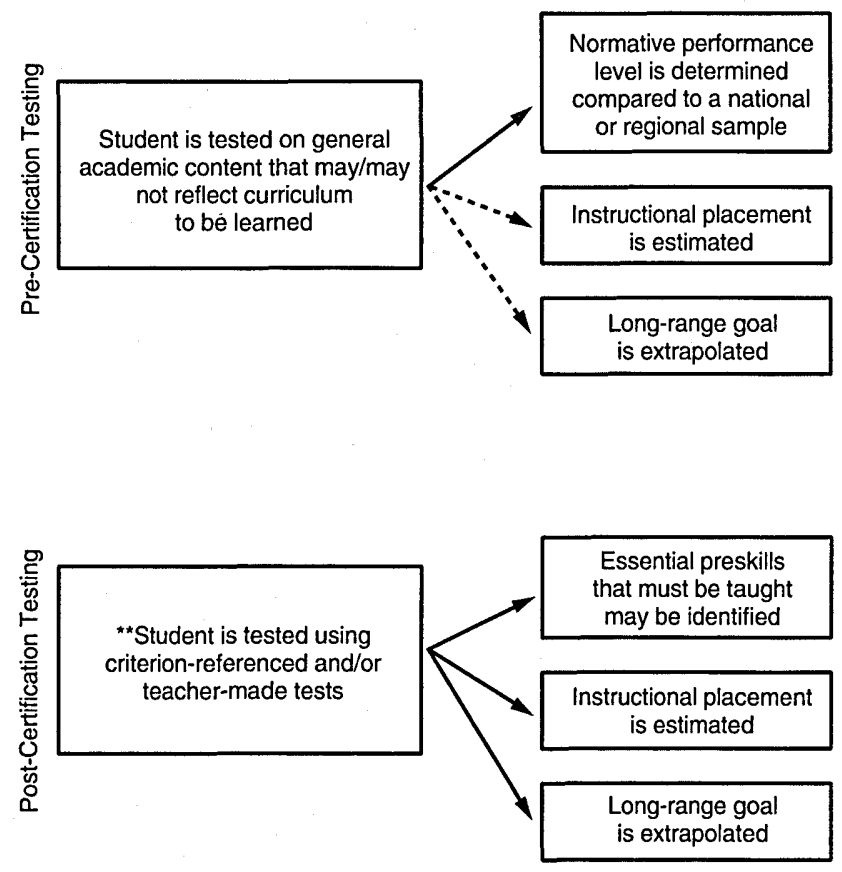

**Solid lines assume tests are content-valid.

FIGURE 1

Current Eligibility Determination and Intervention

Planning Assessment Strategies and Potential Contributions to Problem-Solving Decision Making 
These CBA testing approaches are similar in that they rely on students' curriculum as the basis for constructing testing materials and decision making. The approaches differ on a number of critical dimensions, however, including philosophical assumptions underlying the assessment process, kinds of data collected, availability of technical adequacy data, and decision-making focus (for more detail, see Shinn, Rosenfield, \& Knutson, 1989). Each CBA approach is designed to affect and improve academic interventions. Exactly how this is accomplished differs, though. Pragmatically, the approaches are not competitive; they can be used collaboratively and comprehensively to plan and evaluate academic interventions.

With the exception of CBM, CBA approaches emphasize the collection of student performance data for intervention planning that are not directly useful or validated for determining special education eligibility (Shinn, Rosenfield, \& Knutson, 1989; Shinn \& Good, in press). The procedures emphasize information useful for planning the instructional content (the "what to teach" component) of an intervention plan. The assessment strategies correspond to the kinds of information collected by special education teachers after the certification decision is made, as represented in Figure 1. Sequentially, the timing of CBA data collection need not occur after the eligibility determination, though.

At best, these CBA approaches contribute only indirectly to special education certification decisions. Therefore, the direct linkage between special education eligibility and intervention-one of the quality assessment indicators proposed by Reschly et al. (1988c) -is not evident. Furthermore, most CBA strategies have not been demonstrated to be useful for evaluating the effectiveness of interventions for specific students. As a result, they fail to meet Reschly et al.'s (1988c) second criterion for good assessment practice.

\section{CURRICULUM-BASED MEASUREMENT}

Curriculum-Based Measurement is the only CBA strategy to meet Reschly et al.'s criteria of linking information collected for eligibility determination to intervention planning and usefulness for evaluating intervention effectiveness. As developed by Deno $(1985,1986,1989)$ and others (e.g., Fuchs, 1989, Fuchs, Hamlett, Fuchs, Stecker, \& Ferguson, 1988; Germann \& Tindal, 1985; Marston \& Magnusson, 1985; Shinn, 1989a; Wesson, 1987), CBM is a set of shortduration (1-3 minutes) fluency tests in the basic skill areas of reading, spelling, mathematics computation, and written expression, used in a standardized manner to facilitate problem-solving assessment.

The basic CBM measures, testing durations, scoring metrics, and sample investigations of their technical adequacy (reliability and validity) are presented in Table 1 . An extensive program of research has been conducted for more than 12 years supporting these measures as reliable and valid indicators of student progress in the basic skill areas. For example, in reading, the number of words read correctly has been validated as an accurate measure of a student's general reading skill, including reading comprehension. For more detail on technical adequacy, see the extensive review by Marston (1989).

In contrast to Figure 1, CBM links the assessment data collected for special education (or other special programs) eligibility to intervention by testing a referred student repeatedly in successive levels of the general education curriculum in which the student is having difficulty. This testing process is called Survey-Level Assessment (SLA). As with PNTs, data derived from CBM SLA may assist in determing a student's eligibility for special education services by providing an index of normative performance. Rather than testing referred students on tests assumed to be contentvalid and making comparisons to a norm group that may or may not represent the referred students' learning experiences and opportunities within the specific curriculum,

\section{TABLE 1}

A Description of the Basic Curriculum-Based Measures In Reading, Spelling, Mathematics Computation, and Written Expression

\begin{tabular}{|c|c|c|c|}
\hline Area & $\begin{array}{l}\text { Testing } \\
\text { Duration }\end{array}$ & $\begin{array}{l}\text { Description } \\
\text { and Types of } \\
\text { Scores Derived }\end{array}$ & $\begin{array}{c}\text { Sample } \\
\text { Technical Adequacy } \\
\text { Information }\end{array}$ \\
\hline Reading & 1 minute & $\begin{array}{l}\text { Students read } \\
\text { passages orally, and the } \\
\text { number of words read } \\
\text { correctly and } \\
\text { errors are counted. }\end{array}$ & $\begin{array}{l}\text { Deno, Mirkin, \& } \\
\text { Chiang (1982); } \\
\text { Fuchs, Fuchs, \& } \\
\text { Maxwell (1988) }\end{array}$ \\
\hline Spelling & 2 minutes & $\begin{array}{l}\text { Students write words that } \\
\text { are dictated orally, and the } \\
\text { number of words spelled } \\
\text { correctly and correct letter } \\
\text { sequences are counted. }\end{array}$ & $\begin{array}{l}\text { Deno, Marston, } \\
\text { Mirkin, Lowry, } \\
\text { Sindelar, \& } \\
\text { Jenkins (1982); } \\
\text { Marston, Lowry, } \\
\text { Deno, \& Mirkin } \\
\text { (1981) }\end{array}$ \\
\hline
\end{tabular}

Mathematics $2-5$ minutes Students write answers Computation to computation problems, and number of correct digits are counted.

Fuchs \& Fuchs (1987a); Marston, Fuchs, \& Deno (1986)

Written 3 minutes After being given a story Expression starter or topic sentence, students write a story. Number of words written, spelled correctly, and correct word sequences may be counted. 
CBM tests students in the curriculum they are expected to learn. Performance is then compared directly to how other students perform in that curriculum. And while CBM provides equivalent, but more direct information for eligibility, the data also allow for initial decisions about intervention to be made, as presented in Figure 2.

By testing students in successive levels of the curriculum, the level in which a student performs successfully can be identified for instructional placement purposes. This strategy of directly testing students until they are successful is in stark contrast to PNTs, which usually confirm that the referred student is unsuccessful on the test tasks. SLA also facilitates discussion of the level of the curriculum in which the student would be expected to perform in 1 year. Once this curriculum level has been identified, the annual goal of the individualized education program (IEP) can be written. Once goals have been established, the initial intervention plan can be evaluated on a continuous and frequent basis, allowing ineffective interventions to be identified and modified and effective treatments to be continued with confidence. Finally, the extensive amount of information about how the student performs (i.e., what the student does/does not do successfully) in the curriculum can be analyzed to form hypotheses about what essential curricular skills the student already has mastered and those that must be taught.

\section{Basic Assumptions of CBM and Problem-Solving Assessment}

The use of CBM is more than just employing a new set of "tests." Instead, it is a commitment to a new way of viewing school problems and their solutions through a ProblemSolving model (Deno, 1989; Shinn \& Good, in press). The Problem-Solving model is predicated on seven assumptions.

First is an inherent assumption that special education, like other remedial programs, is a problem-solving system for general education. It is designed to remediate some of the problems that general education, as currently structured, is ill equipped to resolve. For example, general education in most schools is not designed to meet the needs a population with diverse academic skills (Gerber \& Semmel, 1984). Special education for students with mild handicaps attempts to remediate many of these problems.

Second, problems are defined situationally. A problem is defined as a significant discrepancy between what is expected in the environment and what occurs. Academic problems are defined by the lack of success for a specific student within a specific general education curriculum compared to students in that same environment who are performing successfully in the curriculum. Therefore, problems have to be defined by the discrepancy in the general education curricu-

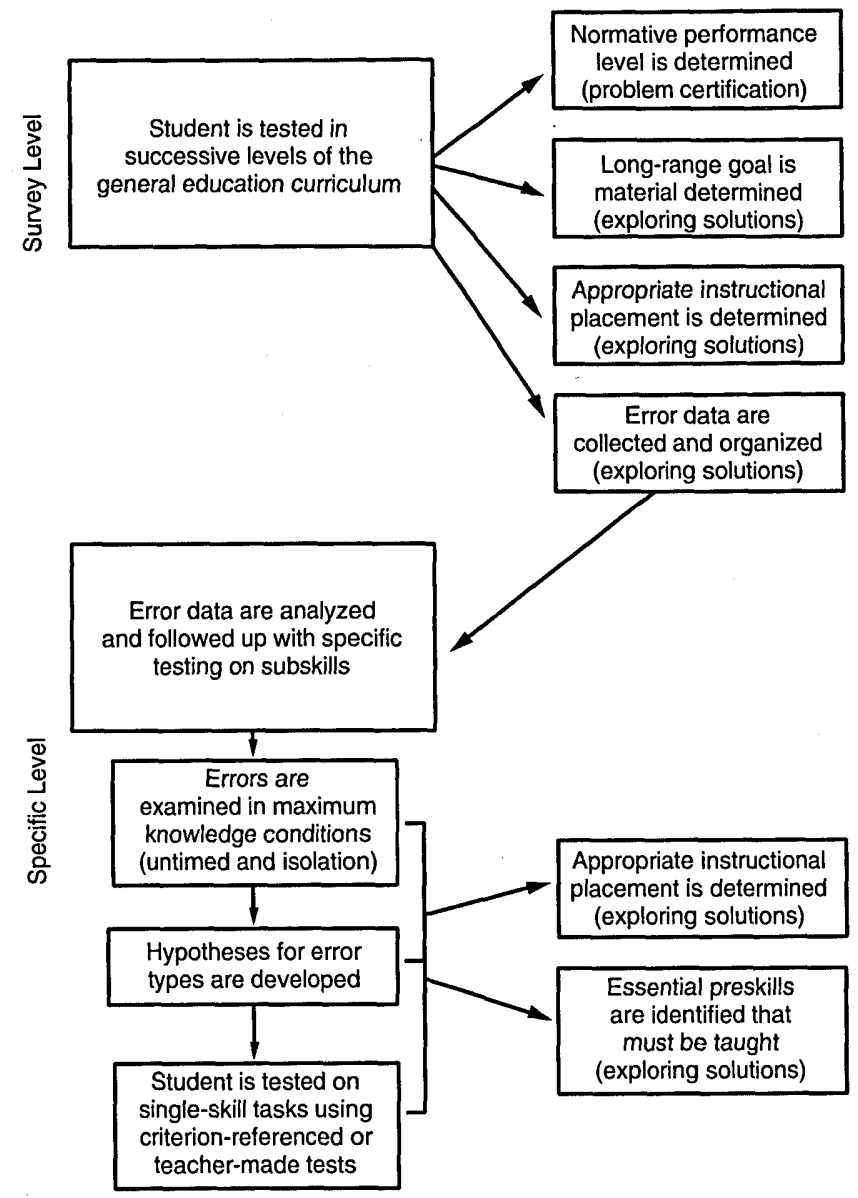

FIGURE 2

Linking Eligibility Determination and Intervention

lum compared to peers rather than an internal discrepancy residing within the student. When situations change, what was a problem may no longer be one and vice versa.

Third, the Problem-Solving model takes a value position that some students need additional resources (e.g., special education) to profit from education. Although decisions about who needs additional resources can be data-based, changes in financial resources, service delivery models, or the knowledge base may result in a change in our conceptions as to who receives special education services.

Fourth, identifying problems is not enough; special education, in and of itself, is not an intervention. As a result, interventions have to be planned in detail.

Fifth, with our current assessment technology and scientific data base, unfortunately, we cannot predict with certainty an intervention that will be effective with any given 
student. Based on test results, we cannot identify a student as an auditory learner or a sequential learner and prescribe the intervention that is certain to work (for more information, see Deno, 1990).

Sixth, because of the uncertain effects of any intervention, the treatment outcomes for specific students must be evaluated frequently and in a timely manner. Effective interventions should be maintained. Ineffective interventions should be modified as soon as possible.

Seventh, problems are resolved when the discrepancy between what is expected and what occurs is no longer significant. For academic problems, typically, that means that a student performs in the general education curriculum at a level commensurate with peers in the same environment.

\section{Steps and Issues}

The Problem-Solving model is divided into five sequential steps, presented in Table 2. Each step is characterized by a different set of conceptual issues that dictate collection of different types of CBM data.

\section{Specific CBM Problem-Solving Procedures}

\section{Problem Identification and Certification}

A potential need for additional instructional resources to resolve an academic problem typically is stimulated by a general education teacher making a referral for assistance to a specialized remedial program such as Chapter 1 or special education. Referral to assistance programs such as Chapter 1 is relatively uncontroversial. Referral to special education has been and remains controversial, in large part because of the stigmatizing labels used and the testing procedures by which those labels are decided. Nevertheless, dramatic changes are needed in determining who receives special education services, and such services unfortunately must be accompanied by labels that place the problem solely within the student (e.g., learning disabilities).

As with any program with limited resources, educators must determine who needs specialized assistance so students may benefit from their education. It has been argued persuasively (e.g., Gerber \& Semmel, 1984) and from a data-based perspective that schools serve students with severe achievement needs in special education programs. For example, Shinn, Tindal, and Spira (1987) demonstrated that students referred by their general education teachers for learning disabilities services in reading typically perform below the 5th percentile, compared to local norms in the reading curriculum. Other studies have demonstrated that students actually placed in learning disabilities programs typically perform below the 3rd percentile, compared to local norms in the curriculum (Shinn, Tindal, Spira, \& Marston, 1987).

\begin{tabular}{|c|c|c|}
\hline \multicolumn{3}{|c|}{ TABLE 2} \\
\hline \multicolumn{3}{|c|}{$\begin{array}{l}\text { CBM Problem-Solving Model Decisions, } \\
\text { Measurement Activities, and Evaluation Activities }\end{array}$} \\
\hline $\begin{array}{l}\text { Problem-Solving } \\
\text { Decision }\end{array}$ & $\begin{array}{l}\text { Measurement } \\
\text { Activities }\end{array}$ & $\begin{array}{l}\text { Evaluation } \\
\text { Activities }\end{array}$ \\
\hline $\begin{array}{l}\text { 1. Problem } \\
\text { identification } \\
\text { (Screening) }\end{array}$ & $\begin{array}{l}\text { Observe and record } \\
\text { student differences, if } \\
\text { any, between actual and } \\
\text { expected performance. }\end{array}$ & $\begin{array}{l}\text { Decide that a } \\
\text { performance } \\
\text { discrepancy exists. }\end{array}$ \\
\hline
\end{tabular}

2. Problem Describe the differences certification (Eligibility between actual and determination) expected performance in context of the likelihood of general education resources solving the problem.

\section{Exploring alternative solutions (IEP goal setting and intervention planning)}

4. Evaluating solutions and making modifications (progress monitoring)

\section{Problem solution Observe and record (program termination) student differences, if any, between actual and expected performance.}

Decide if discrepancies are important enough that special services may be required to resolve problems.
Select the program reform (i.e., intervention) to be tested.

Determine whether intervention is effective or should be modified.

Decide that exisiting discrepancies, if any, are not important and program may be terminated.
Source: From "Curriculum-Based Measurement and Alternative Special Education Services: A Fundamental and Direct Relationship" (p. 13) by S. L. Deno, 1989, Curriculum-Based Measurement: Assessing Special Children, edited by M. R. Shinn, New York: Guilford Press. Copyright (C1989 by The Guilford Press. Adapted by permission.

The Problem-Solving model begins with a decision that a potential problem is important enough to investigate further. At the point that someone (often a general education teacher) has concerns over performance in the curriculum, CBM can be used to determine if the student's skills are sufficiently different from other students to warrant further investigation. As shown in Table 2, a problem is defined as a significant difference between expected performance in the general education curriculum and how the referred student performs. CBM is used to operationalize this conceptual model by having referred students take probes derived from the general education curriculum that typical students are expected to learn. The referred student's scores then are compared to local norms developed from same-grade peers using those same probes.

Consider the case of Desireé, a third-grade student referred because her classroom teacher had serious concerns 
about progress in reading and mathematics. Because no obvious reasons could explain the teacher's concerns (e.g., poor school attendance, vision or hearing difficulties), Desireé was tested using a series of probes derived from her general education reading (Ginn) and math (Heath) curricula. Typical third-grade students were expected to be reading Ginn Level 8, and school district norms had been developed on this level of the reading series (see Shinn, 1989b, for more detail on the local norming process). Desiree read three different passages each day for 3 days in a 5-day period. Her nine scores are presented in Table 3 and summarized by determining her median performance across the passages.

Desiree also completed three different forms of probes derived from the computational objectives for the Grade 3 Heath curriculum. Her scores on these probes also are presented in Table 3. To determine if a problem requiring further assessment existed, Desireé's scores were compared to third-grade peers in her school district. The median score of the third-grade local norms also is displayed in Table 3. In this example, if Desireé's scores consistently fell below half the level of typical grade-level peers, a problem worth warranting investigation would be identified.

To facilitate communication with general education teachers, parents, administrators, and the students themselves, the Problem Identification data are displayed graphically. Desireé's results are presented in Figure 3.

Desireé performed consistently below the cutting score only in the area of reading. Although her score in mathematics was below the median of her peers, it was not considered to be sufficiently different from other students to warrant additional investigation. Because all the math probes required Desiree to write answers to the computational problems, however, the specific responses could be analyzed to determine if she had areas of weakness that could be shared with her general education teacher for improved performance.

As a result of the Problem Identification decision-making process, a problem of potentially serious magnitude was observed only in reading. Consequently, Desireé was administered a Survey-Level Assessment from successive levels of her general education curriculum using $C B M$ as part of the Problem Certification decision-making process. As shown in Table 2, Problem Certification is conceptualized as determining if the difference between expected performance and observed performance in the curriculum is serious enough that a multidisciplinary team considers it unlikely that the problem will be resolved in general education. Then the student may be considered eligible for special education, assuming that procedural state and federal requirements are met.

Consider a fifth-grade student who is placed appropriately in a fifth-grade reader. No additional resources should
TABLE 3

\section{Results of CBM Problem Identification for Desireé}

\begin{tabular}{|c|c|c|c|c|c|c|}
\hline $\begin{array}{l}\text { Academic } \\
\text { Area }\end{array}$ & & Day 1 & Day 2 & Day 3 & Median & $\begin{array}{c}\text { Peer } \\
\text { Median }\end{array}$ \\
\hline \multirow[t]{4}{*}{ Reading } & Passage 1 & 22 & 16 & 11 & & \\
\hline & Passage 2 & 14 & 15 & 11 & & \\
\hline & Passage 3 & 18 & 12 & 14 & & \\
\hline & Daily Median & 18 & 15 & 11 & $15 \mathrm{WRC}^{*}$ & 75 WRC \\
\hline Math Grade & 3 Problems & 19 & 20 & 14 & $19 \mathrm{CD}^{\star \star}$ & $26 C D^{\star \star}$ \\
\hline \multicolumn{7}{|c|}{$* \mathrm{WRC}=$ words read correctly } \\
\hline
\end{tabular}

be required in general education for the student to acquire the expected reading skills, assuming instruction is adequate and the student is motivated. The need for additional resources is less clear for a fifth-grade student who is placed appropriately in a third-grade reader. The general education classroom should have resources (e.g., instructional alternatives, peer tutoring or cooperative learning programs, more individualized assistance) to accommodate that student in the general education classroom. In reality, however, the resources to accommodate the student may vary considerably from district to district and even from school to school. As currently structured, general education may not facilitate the student learning the reading curriculum, so additional resources outside of general education may be necessary.

Finally, consider the fifth-grade student who is placed appropriately in a beginning first-grade reader. It seems unlikely that in most settings, at least as currently structured, general education would have sufficient resources to facilitate the student mastering the reading curriculum. In this circumstance, the intensive and extensive resources provided by special education may be required.

The process of Problem Certification decision making using CBM relies on the SLA to identify the magnitude of the problem. In Desireé's case, she was given at least three randomly selected passages in each of a number of successively lower levels of the Ginn reading curriculum. Her scores in Ginn 8 were already available from the Problem Identification process, so the SLA began by testing her at the next lower level (Ginn 7). One of the major goals of the SLA is to determine a level of the curriculum in which Desiree is "successful."

This decision is operationalized in reading by identifying the highest level of the curriculum (i.e., instructional placement) where she could be placed and expected to profit from instruction. If the student were to be placed in thirdthrough sixth-grade material, it would be desirable to be reading 70-100 words correctly per minute with no more 

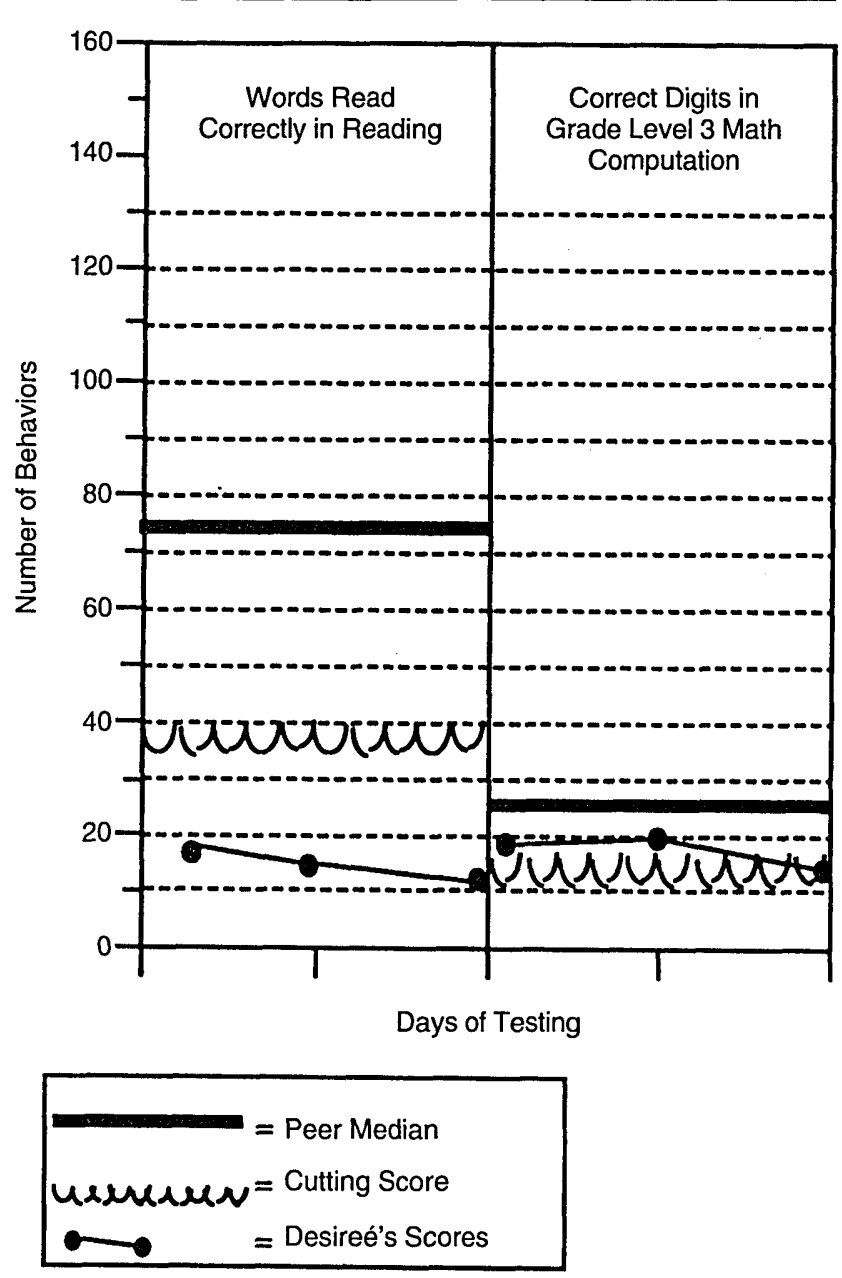

FIGURE 3

\begin{abstract}
Use of CBM Comparing Desiree' to Same-Grade General Education Peers
\end{abstract}

than 4-6 errors (95\% accuracy). If the student were to be placed in first- or second-grade material, it would be desirable to be reading $40-60$ words correctly per minute with no more than 4-6 errors (90\% accuracy).

On a single testing occasion, Desireé read passages beginning at Level 8 through Level 4 . Her scores are shown in Table 4. For ease of interpretation, only the number of words she read correctly are included. According to the reading instructional placement guidelines, Desireé most likely should be placed in a Ginn 4 reader, material expected for typical first-grade students. One conclusion that can be reached is that Desireé performs about 2 years behind curricular expectations in reading.

The potential magnitude of the problem also is defined relative to local normative performance in the reading curriculum. Local norms were developed for the school district from the expected level of the Ginn series representative of each grade. For example, second-grade students were normed using Level 7 of the Ginn curriculum, the expected level representative of most second-grade students during the school year. The appropriate interpretive score is the percentile rank, also shown in Table 4. Desireé performed well below typical third- and second-grade students, but read above the median of typical first-grade students at this time of the school year.

Decisions about Problem Certification using CBM usually are made on the basis of percentile rank criteria (Marston \& Magnusson, 1988; Shinn, 1989b). In Desireé's school district, she could be considered eligible for special education if her scores were below the 16th percentile of students one grade-level below her current grade placement. In this instance, Desireé could be considered eligible because she performed at the 5th percentile of second graders, well below the 16th percentile. Desireé's results in reading compared to the range of reading scores from local norms are presented in Figure 4 . The figure communicates clearly that she performs outside the range of typical third and second graders, but performs above typical first graders in the Ginn series.

Eligibility is but one part of the Problem Certification decision. The second part is need. A student may be eligible for special education, but not need the services. This decision is made only by examining Desireé's instructional needs in the context of resources available in general education that may be used to affect her learning positively. Only after it has been demonstrated to be unlikely that she could benefit from those resources should she be considered for special education. In this case, the multidisciplinary team decided it was unlikely that Desireé would benefit from reading instruction in general education regardless of what

\section{TABLE 4}

Results of Survey-Level Assessment and Problem Certification for Desireé

$\begin{array}{ccccc}\begin{array}{c}\text { Grade } \\ \text { Material } \\ \text { to be Learned }\end{array} & \begin{array}{c}\text { Level of } \\ \text { Ginn } \\ \text { Curriculum }\end{array} & \begin{array}{c}\text { Desireés } \\ \text { Median } \\ \text { Performance }\end{array} & \begin{array}{c}\text { Grade-Level } \\ \text { Peer } \\ \text { Performance }\end{array} & \begin{array}{c}\text { Desireés } \\ \text { Percentile } \\ \text { Rank }\end{array} \\ 3 & 8 & 15 & 87 & 5 \\ 2 & 7 & 20 & \star & \\ 1 & 6 & 22 & 58 & 14 \\ & 5 & 36 & \star & 73\end{array}$

*Local norms, developed from only one level of curriculum per grade level. Therefore, no norms are available for these curriculum levels. 
resources were brought to bear. Therefore, Desireé was provided special education with an IEP in reading.

\section{Exploring and Evaluating Solutions}

The data collected for Problem Identification and Certification decisions are linked directly to Exploring and Evaluating Solutions decisions. In Exploring Solutions, an initial intervention is planned with respect to the "what" to teach (e.g., content of instruction, type and level of curriculum to be used) and the "how" to teach (e.g., what teaching strategies will be used). CBM Problem Identification and Problem Certification data can assist in the intervention planning process by providing information regarding specific skills the student does or does not demonstrate (Howell \& Morehead, 1987; see Figure 2). The major strength of CBM, however, is in evaluating outcomes. CBM was developed to provide teachers with a set of procedures so they may make frequent and routine decisions about whether and when to modify a student's instructional program (Deno, 1985).

In Exploring Solution decisions, the first task is to develop annual goals for the student. Fuchs and Shinn (1989) state that "specification of a goal precedes and defines the CBM monitoring of student progress and instructional effectiveness" (p. 130). A compelling reason to use CBM data to write goals comes from the Education for All Handicapped Children Act (1975). This act requires that an IEP identify each special education student's needs in terms of goals and objectives (Bateman \& Herr, 1981) and identify "appropriate criteria and evaluation procedures" for determining progress toward these goals (Sect. 121a.316e). Yet, almost 16 years after implementation of the Act, current IEPs fail to demonstrate significant improvement in quality over initial implementation (Smith, 1990). Too often, IEP goals are written without current student performance data. IEP goals are frequently vague, lacking observable, measurable outcomes (e.g., "Will improve 1 year in reading"), or are overly specific and detail a series of short-term instructional objectives (e.g., "Will master C-V-C words with $80 \%$ accuracy"). As a result, systematic evaluation of an individual's special education intervention is precluded.

Writing IEP goals using CBM strategies employs a longterm approach to measurement (Fuchs \& Deno, 1991). A decision is made about where and at what level of success in the general education curriculum the student would be expected to perform in 1 year if the student's program were considered successful. A basic format for IEP annual goals in reading, math, written expression, and spelling is illustrated in Table 5. The basic format includes the academic domain, conditions, student behavior, and criterion for success.

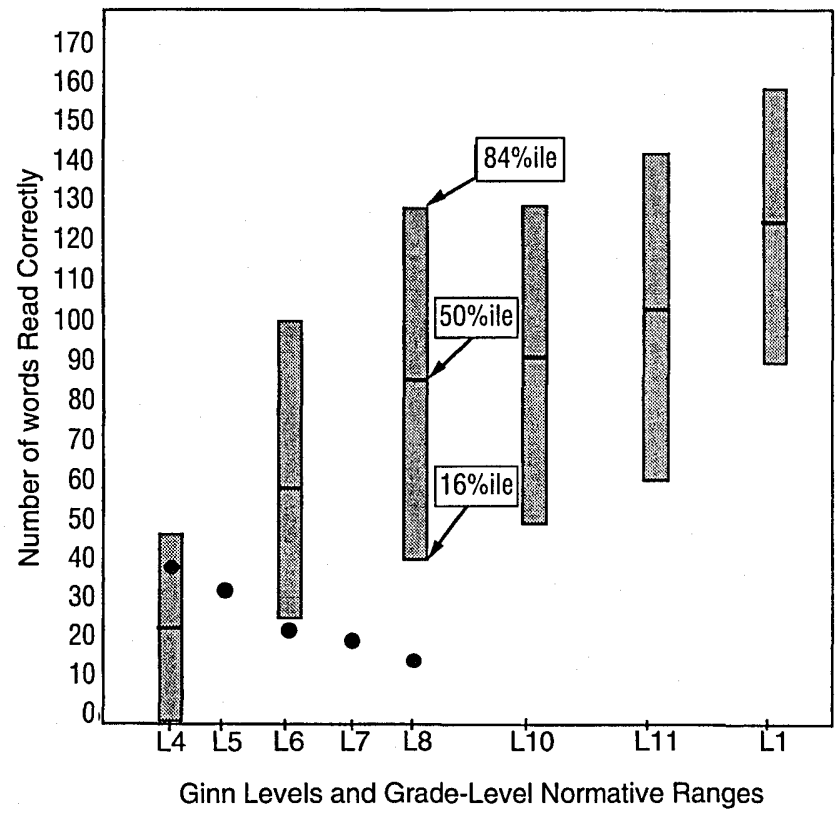

FIGURE 4

\section{Comparing Desireé to Same- and Other-Grade General Education Peers in Reading}

If we consider Desireé's SLA data, it was recommended that she be instructed in Level 4 of the Ginn basal series. After 1 year, if Desiree performs at the rate of progress expected of any student according to the publisher's scopeand-sequence chart, she would be expected to be placed in a Ginn Level 7 reader. The multidisciplinary team decided this expected rate of progress would be appropriate for Desireé. Thus, the long-term goal material identified for her annual IEP goal was Level 7. Next, the criterion for success must be identified. For Desiree, the multidisciplinary team used instructional placement standards (see Fuchs \& Shinn, 1989 , for more detail) and selected the upper end of the range for grades 1-2 material (60 WCM) as the criterion for success. After discussion of the SLA data, the Ginn scopeand-sequence expectations, and the specific expectations for Desireé, the following annual IEP goal was written:

In 32 weeks, when given a randomly selected passage from Level 7 of the Ginn reading series, Desireé will read aloud at a rate of 60 words per minute correct with 4 or fewer errors.

One advantage of measuring Desireé's reading proficiency in long-term goal material is the emphasis on broad, rather than specific, curricular achievement (Fuchs \& Fuchs, 1986a; Fuchs \& Deno, 1991). In addition, measuring Desireé's performance in annual goal material, in contrast to 
short-term objectives, is more logistically feasible, assesses for retention and generalization, represents meaningful growth in the curriculum, and is supported by technical adequacy data (for more detail see Fuchs, in press; Fuchs \& Deno, 1991).

Writing IEP goals using CBM data can be accomplished through a variety of strategies. The first set of strategies involves establishing the IEP annual goal(s) in the absence of local norms. These strategies include expert judgment, dynamic aim, and instructional placement standards.

The second strategy utilizes local norms to establish the criterion for success. All the strategies use the information collected from the SLA data, as this provides the legally required current performance data across levels of the curriculum.

Goal-writing strategies without local norms. The use of "expert judgment" is premised on the expectation that the student will "do more in more difficult material" in 1 year. The multidisciplinary team makes a "best guess" about the annual goal material, the level of the curriculum at which the student would be expected to be performing in 1 year. This level becomes the measurement material for evaluating student progress. A criterion for success also must be specified. As broad guidelines for using the expert judgment approach: (a) the annual goal material must be at least one curriculum level beyond the student's current instructional placement, and (b) the criterion for success must be higher than the student's current performance in the annual goal material (Fuchs \& Fuchs, 1986a). In the case of Desireé, this strategy would require selecting, at the very minimum, Level 5 as the annual goal material and a criterion for success greater than 36 WPM. Goals written using this method usually are significantly more ambitious than these minimal standards. In the absence of more objective data (e.g., instructional placement criteria, local norms), this strategy is straightforward and encourages writing ambitious and realistic goals.

The dynamic aim approach is a variation of the expert judgment approach. This strategy originates with the original "best guess," but the criterion for success is adjusted based on the student's rate of progress. For example, suppose Desireé's IEP goal stated that in 1 year, given passages from Ginn Level 6, Desireé will read aloud at a rate of $50 \mathrm{WPM}$ with 4 or fewer errors. The dynamic aim approach would require frequently evaluating Desireé's performance compared to the goal of 50 WPM and adjusting the criterion for success (i.e., $50 \mathrm{WPM}$ ) based on her projected rate of progress. If her rate of progress suggests that she will exceed 50 WPM, the goal would be raised. On the other hand, if her rate of progress suggests that she will not meet the goal, the 50 WPM goal would be retained and an instructional change would be made. Teachers who utilize a dynamic aim approach have been shown to raise goals more frequently, employ more ambitious goals, and obtain greater student achievement outcomes, as compared to teachers using an approach in which goals are not raised if rate of progress exceeds the goal (Fuchs, Fuchs, \& Hamlett, 1989b).

A third strategy involves using instructional placement standards as guidelines for determining the level of the general education curriculum in which a student would be placed for instructional purposes, the annual goal level of the curriculum, and the criterion for success. To date, CBM

\section{TABLE 5}

\section{Basic Format for Annual IEP Goals in Reading, Math, Written Expression and Spelling}

\section{Academic Area}

Reading

Math

Written Expression

Spelling

\section{Conditions}

In (number of weeks until annual review), when given a randomly selected passage from (level and name of reading series),

In (number of weeks until annual review), when given randomly selected problems from (level and name of math series) for 2 minutes,

In (number of weeks until annual review), when given a story starter or topic sentence and 3 minutes in which to write,

In (number of weeks until annual review), when dictated randomly selected words from (level and name of spelling series) for 2 minutes,

\section{Behavior}

student will read aloud

student will write

student will write

student will write
Criterion

at (number of words per minute correct/\# of errors).

(number of correct digits).

a total of (number of words or letter sequences).

(number of correct letter sequences).

Source: From "Writing CBM IEP Objectives" (p. 136) by L. S. Fuchs and M. R. Shinn, 1989, Curriculum-Based Measurement: Assessing Special Children, edited by M.R. Shinn. New York: Guilford Press. Copyright (C1989 by The Guilford Press. Reprinted by permission. 
instructional placement standards have been proposed only in the area of reading. This approach follows the same general guidelines that were set forth in the expert judgment strategy, but are more data-based. First, the level of the general education curriculum in which the student would be expected to be successful is identified. Although the special education student may not receive instruction in this curriculum, identifying instructional level serves as the index to current performance in the mainstream curriculum. Once that level has been established, the multidisciplinary team can discuss how much progress in the general education curriculum would be expected in 1 year, if the program were successful. The level of the general education curriculum where the student would be expected to perform corresponds to the annual goal material. The criterion for success equals the instructional placement standard for that level of the curriculum (for more detail, see Fuchs \& Shinn, 1989).

As discussed in the section on Problem Identification and Problem Certification, for Desireé, the suggested instructional placement would be Ginn Level 4, because this was the highest level of first- or second-grade curriculum in which she read at least 40 WPM correct. The instructional placement standards also are used as a guideline for determining criteria for success in the IEP goal material. If Level 7 were selected as the annual goal-level material, it would be recommended that Desireé read at least 40 WPM correct as the criterion for success. In Desireé's case, the multidisciplinary team identified the upper end (60 WRC) of the instructional placement standards as the criterion for success.

Goal writing strategies using local norms. The availability of local norms assists with establishing more data-based criteria for success in the annual goal material. Expectations about student progress are tied to the performance of typical general education peers. Guidelines for this approach again require specification of the level of the general education curriculum the student would be expected to be performing in in 1 year. The criterion for success in that material is the median score of typical general education students in that material. For example, if the multidisciplinary team decided that in 1 year Desiree would be expected to perform in the third-grade level of the curriculum (Level 8), the criterion for success would be 87 , the normative score of students at that grade (see Table 5).

\section{Evaluating Solutions}

\section{Procedures for Data Collection}

Once data-based annual IEP goal(s) are written, a standard is provided for evaluating the initial intervention's effectiveness. Effectiveness is evaluated by routinely and fre- quently collecting and analyzing student data. Annual goals in the IEP are translated into a graph to provide a visual representation of the goal and actual student performance, as shown in Figure 5. The graph includes: (a) time frame (horizontal axis), (b) unit of measurement (vertical axis), (c) criterion for success, and (d) current performance data from the material specified in the annual goal (from SLA). The line drawn from the student's current performance data to the criterion for success represents the expected rate of progress, or aimline.

Frequency of measurement. Use of CBM is predicated on the notion that student outcomes are examined on an ongoing and frequent basis. Every time a student is tested, the results are graphed as shown in Figure 6. In Desireé's case, two times each week she was tested by reading a passage randomly sampled from the level of the curriculum specified in her annual IEP goal. In this instance it was Ginn Level 7. As shown in Figure 6, the initial instructional program implemented for 5 weeks was not effective. In fact, the intervention was having a detrimental effect on her reading achievement. Her estimated rate of progress, shown by the trendline, was decreasing. The trendline is drawn through each of Desireé's scores to represent her estimated rate of progress. Because her actual rate of progress was much less than her expected rate of progress, a change in her instructional program was required.

The change in intervention was effective. Not only was Desireé now improving in her general reading skills, but her actual rate of progress was exceeding her expected rate. Collecting student performance data frequently allowed Desireé's teacher to change the instructional program when it was shown to be ineffective.

Determining how frequently CBM data should be collected involves appraising both technical and practical considerations. Technical considerations refer to evidence supporting the use of data to make reliable decisions regarding student progress. The major tool in making this decision is the trendline (Fuchs, 1989). Among the technical issues regarding use of a trendline are the number of data points required to estimate actual progress reliably and how to organize the data for interpretation. An ideal trendline would allow reliable decisions to be made with a few number of data points. This would enable teachers to avoid maintaining an ineffective instructional program for long periods. A minimum of 10 data points (Good \& Shinn, 1990) is necessary to estimate a reliable performance trend.

Practical considerations also are important. Although collecting data on student performance daily may be technically advantageous so that the minimum number of data points for trend estimation can accrue rapidly, this may not be feasible. 


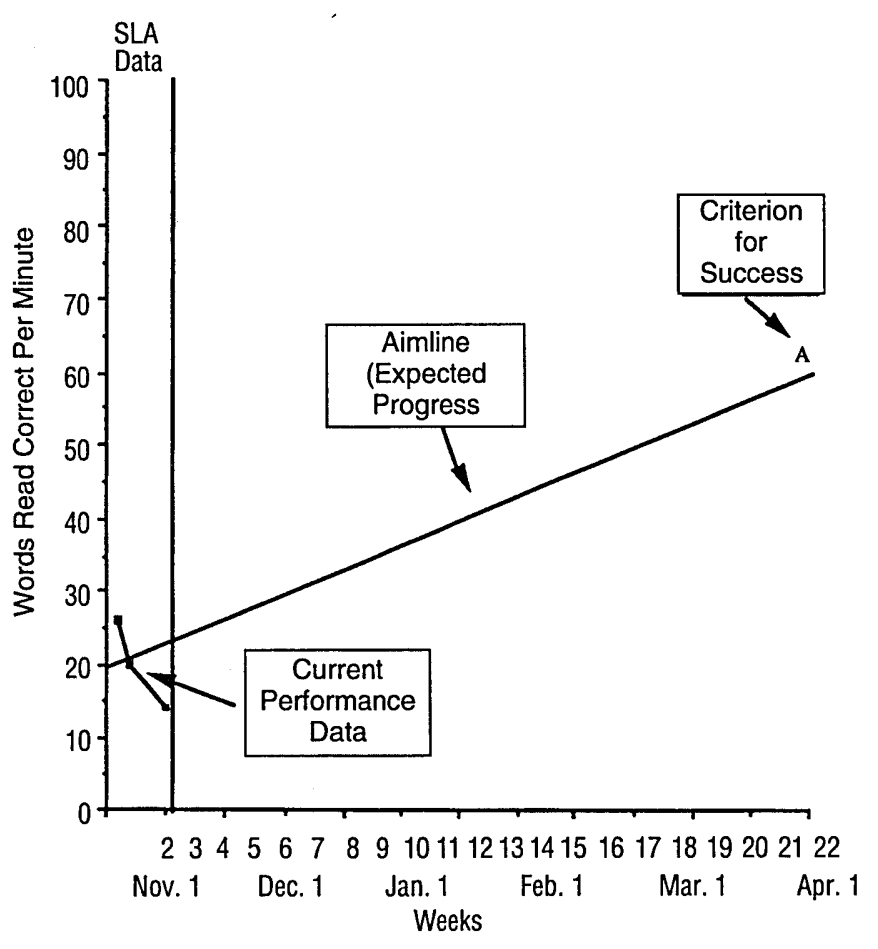

FIGURE 5

Desireé's Annual IEP Goal Translated into a Graph for Monitoring Intervention Effectiveness

Research has suggested that measuring student performance twice weekly may be sufficient to make appropriate decisions (Fuchs \& Fuchs, 1986b). No additional student achievement benefits as a function of frequency of measurement were found for monitoring twice weekly or three times weekly or daily (Fuchs \& Fuchs, 1986b). Therefore, it is recommended that special education practitioners collect student performance data twice weekly so the requisite 10 data points can be collected in a little over a month (5 weeks). This time frame allows adequate time for demonstrating instructional effects and the modification of ineffective programs.

Data collection strategies. Various methods have been utilized to collect CBM student performance data. Most frequently, teachers collect and score the data. The usefulness of having teachers meaningfully involved in collecting and evaluating student data has been documented in terms of greater positive effects on student achievement (Fuchs, Deno, \& Mirkin, 1984; Fuchs \& Fuchs, 1986b). Some special education teachers, however, express reluctance, at least initially, to use CBM progress monitoring strategies because they perceive the amount of time involved to be excessive (Wesson, King, \& Deno, 1984). The perception of progress

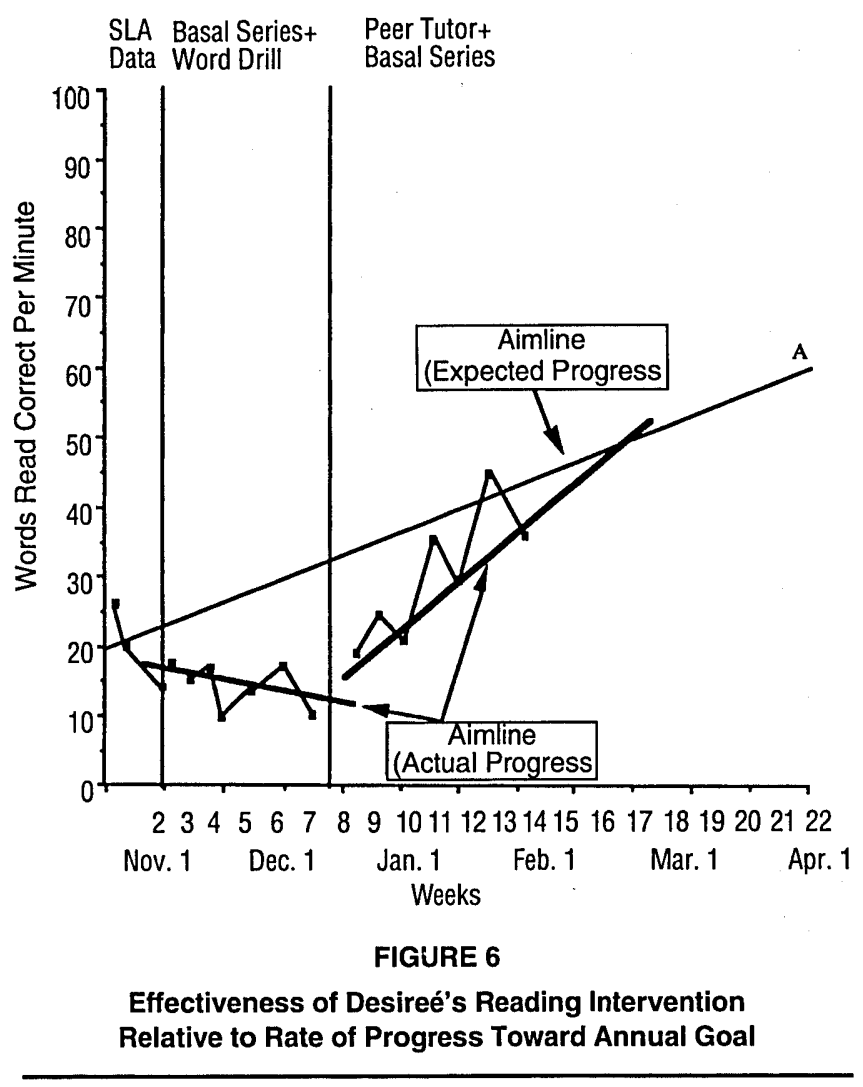

monitoring being time consuming does not match the data, however. Fuchs (1987) found that teachers spent an average of only 2 minutes and 15 seconds collecting a 1-minute sample of reading, including preparation, administration, scoring, and graphing of student data. Other research corroborates these findings for teachers who monitor student progress using CBM (Marston \& Magnusson, 1985; Wesson, Fuchs, Tindal, Mirkin, \& Deno, 1986).

Although it is logistically feasible for teachers to collect, score, and analyze CBM data, other strategies may increase efficiency. One approach has emphasized computer-managed instruction (CMI; Fuchs, 1988), which uses computer software programs to collect, graph, and analyze student performance data (Fuchs, Hamlett, \& Fuchs, 1990). CMI creates an information management system to assist teachers in evaluating students' progress towards the CBM annual IEP goal. In a study that compared utilizing the computer software program to teacher-managed CBM practices (Fuchs, Fuchs, Hamlett, \& Hasselbring, 1987), teachers reported that computers were more efficient than scoring, graphing, and evaluating student data by hand. Although the teachers perceived increased efficiency by using the computer software pro- 
gram, the research results suggested that the use of computers actually decreased teachers' efficiency in implementing the procedures. Using the computer program, however, may minimize teacher time devoted to analyzing student performance (Fuchs, Fuchs, Hamlett \& Hasselbring, 1987).

The use of student peers also has been investigated as an option to reduce teacher data collection time and allow teaches to devote more time to interpreting the obtained information. Moreover, it has been hypothesized that potential benefits to peer tutors from collecting student data may accrue in terms of their own achievement and self-concept gains. Research related to training general education students to monitor reading using $\mathrm{CBM}$ procedures suggests that they can be trained to be reliable data collectors. Trained student monitors have been shown to be as accurate as adults, with interrater agreement percentages between students and trained adults ranging from $96.6 \%$ to $97.7 \%$ (Bentz, Shinn, \& Gleason, 1990) and $86.2 \%$ to $100 \%$ (Knutson, 1990). Concerns have been raised, however, about the amount of time needed to train and frequently monitor student data collectors to assure high levels of reliability over time (Knutson, 1990). Again, in making CBM procedures more timeefficient, the qualitative information that teachers gain through direct scoring of student protocols is forfeited and should be taken into account when considering alternatives.

Determining intervention effectiveness. Data are collected in an ongoing manner to provide information regarding a student's progress toward the annual IEP goal(s). Teachers ultimately must make decisions about whether a program is effective, based on the data. Program effectiveness decisions are made by summarizing actual student performance and choosing an evaluation framework, either goal- or experimental-based.

Summarizing actual student progress is accomplished in two ways: (a) using a split-middle trendline (SM) or (b) using an ordinary-least-squares trendline (OLS). The SM and OLS differ in the way they are calculated. The SM requires few calculations and is trained easily (White, 1974). The OLS requires a programmable calculator or a microcomputer. In a study comparing the accuracy of SM and OLS procedures, results indicated that the OLS method was superior to the SM method for reading CBM data (Good \& Shinn, 1990). More specifically, the OLS estimates were superior in their ability to estimate with smaller numbers of data points (10) and for longer periods into the future (6 weeks). These data suggest that an OLS method for evaluating student performance and making instructional decisions is best.

Goal-based data evaluation is the most common evaluation approach (see Fuchs, Fuchs, \& Hamlett, 1989b). In the goal-based evaluation framework, the annual IEP goal is translated into the aimline of expected rate of progress. This aimline is used as the reference for success and decisions are made according to the student's progress toward this line. This evaluation approach is illustrated in Figure 6. To determine whether Desireé is making progress toward her goal, decision rules are applied when a predetermined number of data points have been collected. The rules applied would be in accordance with the slope of the trendline (either exceeding or failing to meet projected aimline), as explained previously. A variation to using a trendline with this approach is the 3-day rule (see White \& Haring, 1980). The 3-day rule states that if the student's data points fall below the aimline for 3 consecutive monitoring days, an instructional change is warranted. Conversely, if the data points fall above the line for 3 consecutive monitoring days, the goal should be raised.

An experimental-based approach to evaluating student performance (see Hamlett, Fuchs, Stecher, \& Ferguson, Fuchs, 1988) also can be used to determine intervention effectiveness. This approach requires that an instructional change be made after collecting a predetermined number of data points (e.g., 10), regardless of student progress. Changes in student programs are made routinely to: (a) test the effectiveness of different instructional strategies, and (b) potentially effect a greater rate of progress than would be obtained even if an effective program were maintained (Fuchs, 1988). A student's slope of improvement for each intervention is compared to determine which intervention had the greatest effect on student progress. The teaching approach that had the greatest effect on student performance then is implemented. Research comparing the goal-based and experimental-based methods indicates that the goal-based approach has a greater impact on student achievement, and teachers using this approach implement the monitoring and data-management procedures more accurately (Fuchs, 1988).

\section{Problem Solution}

If interventions are effective, educators can expect that ultimately a problem will be resolved. In the Problem-Solving model, this decision is reached when the initial severe discrepancy between what was expected and what was occurring is no longer severe. In special education, this decision is akin to making a decision that a student no longer needs special education services and can benefit from education in the general education classroom. The limited research data on special education exit rates suggest that few students are returned to general education annually (Shinn, 1988; Rodden-Nord, Shinn, \& Good, in press). Whether this outcome is due to the limited effectiveness of special education intervention programs, poor assessment practices, or an interac- 
tion of the two has not been determined. Some school-based personnel (e.g., Allen, 1989) have argued that Problem Solution decisions are not made because relevant data are not collected to suggest that a special education student can perform successfully in the general education curriculum.

CBM can be used to assist in making Problem Solution decisions in two ways. First, student progress toward the annual IEP goal is examined formally. This process entails evaluation of the graphed data, typically in relationship to the expected rate of progress shown by the aimline. In Figure 6 , failure of the intervention implemented initially to resolve Desireé's reading problem was identified as part of the Problem Solution decision in mid-December.

Second, CBM can be used to repeat quarterly the Problem Identification peer-referenced testing activities. Special education students are tested on one day in the typical level of the curriculum from their grade placement and compared to same-grade students. At the time the first peer-referenced testing took place, Desireé had not reduced the discrepancy from her third-grade students as she continued to score at the 5th percentile.

At the time of the annual review, special education students are given another SLA, in which they are tested in successive levels of the curriculum. These data allow decisions to be made regarding reduced discrepancies from same-grade and lower-grade students in the curriculum. The data also serve as current performance data for writing new annual IEP goals.

In Desireé's case, by the end of the school year, not only had she exceeded greatly her expected rate of progress on the IEP but she also had reduced significantly the discrepancy from her peers in the curriculum. At the beginning of the year, she had performed at the 5th percentile of samegrade peers. By the expiration of her IEP, she performed at the 38 th percentile relative to same-grade peers. Because of her rapid rate of progress in special education, as evidenced by the IEP graph and her reduced discrepancy, Desireé was exited from special education.

\section{RESEARCH OUTCOMES OF CBM AND PROBLEM- SOLVING MODEL IMPLEMENTATION}

A number of studies have examined components of CBM implementation (e.g., the effects of specific goal-setting strategies on student achievement in reading) and on implementation of CBM in a Problem-Solving model for special education decision making. The current research results reported here are interpreted in a unit of analysis called effect size (ES). Effect size is determined by taking the difference in scores between group means (e.g., experimental and con- trol groups) divided by the standard deviation of the control group (Kavale \& Forness, 1987). ES will be used to discuss differences in CBM performance for descriptive and experimental studies. For descriptive studies, an ES represents the mean performance differences between groups of students.

For example, Shinn, Ysseldyke, Deno, and Tindal (1986) compared the CBM reading scores of fifth-grade students in learning disabilities programs and other low-achievers. They found an ES of -1.3 . This score is interpreted as meaning that the typical LD student performed 1.3 standard deviations below the typical low achiever on CBM reading probes. In terms of percentile ranks, an ES of this magnitude means that the typical LD student performed at approximately the 10th percentile rank of low-achieving students.

For the experimental studies, Fuchs and Fuchs (1986b) explain an effect size of approximately one-half standard deviation (.52) as meaning that "in terms of the standard normal curve and an achievement test scale with a population mean of 100 and standard deviation of 15 , one might expect the [intervention $\mathrm{X}$ ] to increase the typical achievement outcome score from 100 to approximately 107.5 " (p. 436). Achievement gains of this magnitude suggest that a student who would be expected to perform at the 50th percentile without the treatment would be expected to perform at the 69th percentile with the treatment.

\section{Problem Identification/Problem Certification Research Outcomes}

Outcome investigations regarding the use of CBM to make Problem Identification and Problem Certification decisions have been undertaken in three broad areas: (a) the utility of using CBM measures to differentiate students with mild handicaps (e.g., learning disabilities) from low-achieving and typical general education students, (b) the effects on special education assessment and placement practices, and (c) effects on the practices of school psychologists.

\section{Using CBM to Differentiate Groups of Students}

Four studies have investigated the usefulness of CBM to differentiate students referred for or placed in special education from other groups such as low achievers (e.g., Chapter 1 students) and typical students. One study investigated the achievement characteristics of students referred for special education services in reading. Three studies examined whether CBM provides clear and reliable differentiation among students placed in special education, Chapter 1, and general-education-only students. If the measures are to be validated for Problem Identification and Certification decisions, differences should be observed among groups of students that educators classify differentially. 
The achievement characteristics of students referred for special education because of reading problems were studied by Shinn, Tindal, and Spira (1987). They examined the performance of referred students grades 2-6 on grade-level CBM reading tasks compared to local norms of general education students in the same school district. ESs across grades ranged from -1.6 to -1.0 . When translated into percentiles, these ESs ranged from the 5.5th to the 15.9th percentile. The typical referred student performed at about the 8 th percentile of general education peers. The authors concluded that referred students are characterized by extremely low achievement in the general education curriculum compared to other students and that CBM reliably indexes these achievement differences.

CBM also reliably differentiates groups of students classified by more traditional procedures. As presented earlier, Shinn, Ysseldyke, Deno, and Tindal (1986) found significant differences between LD students and low achievers on CBM reading, spelling, and written expression problems. In reading, the typical fifth-grade LD student across five districts performed at the 9.7 th percentile rank of low-achieving students. More than $90 \%$ of low achievers would be expected to earn CBM reading scores above the typical student placed in LD programs.

Shinn and Marston (1985) researched differences on CBM measures of reading, spelling, math computation, and written expression among students placed in programs for mild handicaps (MH), Chapter 1 students, and typical general education students in grades 4-6. ESs across grades showed that students in $\mathrm{MH}$ programs performed at extremely low levels compared to general education peers and Chapter 1 students. In reading, for example, ESs ranged from -2.3 to -2.4 relative to general education peers; the typical $\mathrm{MH}$ student performed at the 1st percentile of general education students. When MH students were compared to Chapter 1 students, ESs ranged from -.2 to -1.5 , with the differences increasing by grade level; the typical MH student performed at the 17th percentile of Chapter 1 students. More than $83 \%$ of Chapter 1 students outperformed the MH students in reading. Chapter 1 students also were differentiated reliably from general education students. By grade, the ESs ranged from -.9 to -1.5 , with the typical percentile rank corresponding to the 16th percentile compared to general education peers.

Finally, CBM was used to study potential CBM reading differences between all students in a school system, grades 1 to 6, who had been placed in programs for learning disabilities via traditional ability-achievement discrepancy procedures (Shinn, Tindal, Spira, \& Marston, 1987) and Chapter 1 and typical general education students. When comparing LD students to general education peers, ESs ranged from
-1.1 at grade 1 to -2.2 ; the typical LD student performed at the 3rd percentile of general education students. In comparison to Chapter 1 students, ESs ranged from -.2 at grade 1 to -1.5 with the differences increasing by grade level; again, the typical LD student performed at the 17th percentile of Chapter 1 students. As in the previous studies, Chapter 1 students were differentiated reliably from general education students. By grade, the ESs ranged from -.7 to -1.4 with the typical percentile rank corresponding to the 14th percentile compared to general education peers.

In each of these studies, the authors concluded that CBM could be used to differentiate groups into different types of educational services in much the same way as the school had classified students in the past, but more in line with the benefits of the Problem-Solving model approach.

\section{Effects on Assessment and Placement Practices}

Marston and Magnusson (1988) summarized the effects of using CBM within a Problem-Solving model on eligibility assessment and special education placement practices. The number of students referred for special education who actually were assessed for eligibility determination decreased by almost half when systematic Problem Identification decisions were made. In contrast to practices in which almost all referrals are tested for special education eligibility, Marston and Magnusson (1988) reported rates of 45 to $65 \%$ of referred students being tested. Actual eligibility rates also dropped to approximately 25 to $45 \%$ of all referrals-again a figure quite in contrast to national referral placement rates of 75 to $92 \%$ (Algozzine, Christenson, \& Ysseldyke, 1982). Germann and Tindal (1985) reported special education placement figures that closely paralleled their state and national levels.

\section{Effects on School Psychology Practices}

Changes in the assessment and service delivery practices of school psychologists after implementation of CBM within a problem-solving model have been noted by Canter (1991) and Marston and Magnusson (1988). Canter (1991) reported changes in school psychologists' assessment practices. Rather than routinely testing every referral to determine special education eligibility, in the Problem-Solving model school psychologists tested students only when there were specific assessment questions. Only half of the cases on the typical school psychologist's load involved testing, and only half of those involved assessment of learning aptitude (i.e., intelligence). In addition, Canter (1991) detailed qualitative changes in the types of data collected when testing was conducted.

With the decreased time in routine eligibility testing, Marston and Magnusson (1988) observed corresponding in- 
creases in school psychologists' consultation activities from 12 to $36 \%$ of their time within 3 years, and a similar increase from 1.5 to $10 \%$ for direct services (e.g., counseling). Canter (1991) reported that in subsequent years school psychologists' consultation time increased further to $52 \%$ of their time.

\section{Exploring and Evaluating Solutions}

The outcomes of using CBM to write data-based annual IEP goals and monitor intervention effectiveness have been examined in three broad areas: (a) student achievement outcomes, (b) changes in teaching practices, and (c) students' goal awareness. Most of the experimental work has been conducted by Lynn Fuchs and associates at Vanderbilt University and typically are interpreted as ES units.

\section{Effects on Student Achievement}

A number of studies have demonstrated effect sizes related to student achievement and CBM. These studies, summarized in Table 6, include the use of CBM procedures to monitor student achievement by having teachers collect CBM data: (a) without instruction on how to use the information (informal decision making), (b) with systematic rules for making intervention effectiveness decisions and instructional changes, and (c) by providing feedback about how the students' performed on specific required curricular skills (instructional enhancements).

These studies indicate, at a broad level, that the ESs associated with using CBM and data evaluation and decision rules produce significant and socially meaningful achievement gains. Most of the studies comparing the role of feedback systems (i.e., feedback regarding programmatic changes, qualitative feedback on student progress, and so on) indicate that teacher involvement in the evaluation process has a greater influence on student achievement than measurement that does not require teacher involvement.

Informal decision making regarding student progress. The process of collecting CBM student performance data without specific decision-making strategies for determining when a program is ineffective and requires modification seems to have mild effects on student achievement. Overall, individuals whose progress is monitored using CBM over time can be expected to make modest gains (average ES = .36 , increases from 50 th to 63 rd percentile) over those students whose progress is monitored using traditional methods (e.g., teacher judgment, student workbooks, and so on). In some circumstances, using CBM without specific strategies to make program improvements does not impact student achievement. For example, in a study by Fuchs, Fuchs, and Hamlett (1989c), an ES of .36 was found not to be reliably different from students whose progress was monitored using traditional methods. In a meta-analysis of systematic formative evaluation studies, ESs up to .70 (i.e., increases from 50 th to 76 th percentile) have been noted, but how many studies included a data collection-only group is unclear (Fuchs \& Fuchs, 1986b).

Systematic decision-making strategies. Student achievement can be maximized by using CBM data and systematic decision rules to indicate when a change in an instructional program is required. Several studies have investigated systematic strategies designed to get teachers to make instructional changes in response to students' progress. The research has focused on feedback methods indicating to teachers that an instructional program is ineffective and a change is due, including: (a) the amount and type of feedback given regarding programmatic changes and student performance, and (b) the type of goal structure used.

Most frequently, computers have been used to indicate when an instructional change is required (e.g., Fuchs, Fuchs, \& Hamlett, 1989d). The computer compares a student's actual rate of progress with the expected rate of progress toward the IEP annual goal. When actual progress is less than expected progress, the computer signals to teachers that a program change is required. Outcomes of using CBM and this computer feedback system are ESs in the magnitude of .72. This growth represents an increase from the 50th to the 77 th percentile, compared to using traditional methods. Other research has explored using computer feedback after teachers make initial program effectiveness decisions. In the area of spelling, Fuchs, Fuchs, and Hamlett (1989a). provided feedback to teachers by the computer automatically or required teachers to make an initial decision about when and what to change. The computer then gave feedback regarding the correctness of the teacher's initial decision. Results indicated that spelling achievement was greater with students of teachers who were required to make initial decisions with subsequent computer feedback.

Varying computer feedback using different CBM goal structures also has been explored. Fuchs, Fuchs, and Hamlett (1989b) compared a dynamic goal structure approach to a static goal structure approach. The computerized feedback was the same for both groups, but the dynamic goal structure group received computerized feedback that required teachers to raise the goal when estimated student progress exceeded the aimline. The static goal structure did not require the teachers to increase goals in response to progress that exceeded the anticipated aimline. The results indicated that the dynamic goal approach had greater effects on student achievement than the static goal structure or the control group as measured by CBM math measures (Fuchs, Fuchs, \& Hamlett, 1989b). 
TABLE 6

\section{Summary of Effect Sizes Related to Student Achievement and Curriculum-Based Measurement \\ Study \\ Domain \\ Group or Experimental Conditions}

Fuchs \& Fuchs (1986b)

Fuchs \& Fuchs (1987b)

Fuchs, Deno, \& Mirkin

(1984)

Fuchs (1988)

Fuchs, Fuchs, \& Hamlett

(1989d)

Fuchs, Fuchs, \& Hamlett

(1989a)

Fuchs, Fuchs, \& Hamlett

(1989c)

Fuchs, Fuchs, \& Hamlett

(1989b)

Fuchs, Fuchs, Hamlett, \&

Stecker (1990)
Meta-analysis of systematic formative evaluation

Meta-analysis of graphing student data

Reading

Spelling

Reading

Spelling

Reading

Math

Math
Effect Size

Effects on achievement using progress monitoring

Effects on achievement using data evaluation and decision rules

Effects on achievement using teacher judgment

Effects on achievement using graphic display

Effects on achievement using recorded data

Effects on achievement using equal-interval paper

Effects on achievement using ratio-scaled paper

G1. CBM monitoring

G2. Traditional monitoring

G1. Goal-based structure

G2. Experimental structure

G1. Performance + quality feedback

G2. Performance only

G1. Enhanced feedback CBM

G2. Unenhanced feedback CBM

G3. Control

G1. Measurement + evaluation

G2. Measurement only

G3. Control

G1. Dynamic goal structure

G2. Static goal structure

G3. Control

G1. Performance + skills analysis

G2. Performance only

G3. Control
Average $=.70$

Average $=.91$

Average $=.42$

Average $=.70$

Average $=.26$

Average $=.46$

Average $=.53$

Words read

correctly $=.34$

*WSC $=2.84$

${ }^{\star \star} \mathrm{CLS}=2.49$

Retell matched words $=.67$

1 vs. $3=.45$

1 vs. $2=.22$

2 vs. $3=.23$

1 vs. $3=.72$

1 vs. $2=.21$

2 vs. $3=.36$

1 vs. $3=.52$

1 vs. $2=.28$

2 vs. $3=.25$

1 vs. $3=.67$

1 vs. $2=.55$

2 vs. $3=.26$

$* \mathrm{WSC}=$ words spelled correctly

${ }^{* *} \mathrm{CLS}=$ correct letter sequences

The effect size magnitude associated with the dynamic goal CBM procedures was .52 (approximately one half standard deviation), or the difference from the 50th to the 69th percentile.

Instructional enhancements. Research on CBM and in Exploring and Evaluating Solutions, to this point, has examined the outcomes of collecting CBM data with informal and systematic decision-making strategies. The latter were designed to tell teachers explicitly that instructional changes are necessary because the current instructional program was not effective. The focus of decision making has been on the when to change rather than what to change. Use of CBM has been explored further in terms of providing specific information designed to tell teachers what parts of their instruc- tional program to change. This type of information is referred to as a skills analysis, or an instructional enhancement. Most often, teachers have been provided with skills analysis information obtained from the student's performance on weekly probes. The skills analysis gives teachers specific information regarding skills required in the curriculum that have/have not been demonstrated. As shown in Table 6, research in this area corroborates earlier findings that teachers who use direct and frequent measurement affect student outcomes to a greater degree than teachers who use traditional means of monitoring progress.

In the areas of math and reading, teachers who use CBM and receive skills analysis information effected greater 
growth, compared to teachers who monitored and evaluated student progress and the control group (Fuchs, Fuchs, \& Hamlett 1989d; Fuchs, Fuchs, \& Hamlett, \& Stecker, 1990). The skills analysis information for math included specific math problem types (e.g., addition basic facts, sums to 18) that were attempted at least $75 \%$ of the time on the probes with at least $85 \%$ accuracy. The ES magnitude associated with CBM skills analysis was .67 compared to the control group, and .55 compared to CBM teachers who did not receive the skills analysis. In reading, the skills analysis information consisted of a structured analysis of story components included in students' recalls. The ES magnitude associated with CBM skills analysis was .67 compared to CBM teachers who did not receive the skills analysis. In terms of the standard normal curve, this result would be associated with increases from the 50th to the 75th percentile.

Research in spelling indicates that CBM skills analysis can effect student achievment, but the skills analysis information does not have to include recommendations as to what to change (Fuchs, Fuchs, Hamlett, \& Allinder, 1991a; 1991b). Fuchs, Fuchs, Hamlett, and Allinder (1991a) demonstrated support for earlier findings that CBM skills analysis effects greater student achievement. The skills analysis information provided teachers the lists of words administered to the student, the student's response, and the three most frequent types of errors the student had made. A variation of the skills analysis information in spelling was explored by providing the teacher a recommended teaching adjustment along with detailed instructions for how to implement it (Fuchs, Fuchs, Hamlett, \& Allinder, 1991b). When compared to teachers employing traditional monitoring strategies, teachers who received skills analysis information versus teachers who received the revised skills analysis information both showed greater achievement gains, but did not significantly differ from each other. The comparability of the two CBM groups may suggest that in the area of spelling, specific recommendations for instructional planning may not be necessary or sufficient.

\section{Effects on Students' Goal Awareness}

Students' knowledge of their progress generally has been suggested as a means of making the student aware of teachers' expectations, offering motivation as a means of accomplishing their goal, and in some way serving as an exercise in self-monitoring. Erez (1977), for example, suggests that goals and knowledge of performance toward goals are necessary to improve student performance.

In a study examining the effects of CBM on teacher behavior and student achievement (Fuchs, Deno, \& Mirkin, 1984), student awareness of learning also was examined. Awareness was measured by asking students if they knew their goals and if they could judge whether they would meet their goals. Results indicated that students who were monitored using CBM procedures in reading were more knowledgeable about their learning. Similarly, students using CBM in spelling described their goals more specifically than students who were monitored using traditional methods (Fuchs, Butterworth, \& Fuchs, 1989). In addition, achievement gains were greater for students in the CBM groups than students being monitored using traditional methods. It was suggested that the differences in achievement gains were not attributable to differences in student perceptions of goal attainment but, rather, that they may be related to the student's knowledge of goals and perceptions of teacher feedback concerning progress (Fuchs, Butterworth, \& Fuchs, 1989).

\section{Effects on Teaching Practices}

Although much attention has been directed at student achievement outcomes, teacher behavior also has been shown to be affected by CBM monitoring procedures. Changes have been demonstrated in terms of compliance with CBM procedures, responding to student data, and varying individual instructional planning and delivery.

The extent to which teachers implement CBM procedures has been determined most commonly using the Modified Accuracy of Implementation Rating Scale (MAIRS; Fuchs, 1986). This scale consists of 11 items assessing compliance with each component of the CBM procedure, ranging from placing students in goal-level material to changing instructional programs when told to do so. The degree to which teachers comply with the CBM procedures has been comparable across a variety of experimental conditions (Fuchs, Fuchs, Hamlett, \& Allinder, 1991b; Fuchs, Fuchs, Hamlett, \& Stecker, 1990; Fuchs, Fuchs, \& Hamlett, 1989b; Fuchs, 1988). But differences in compliance have been found, relating to evaluation approach (e.g., goal- versus experimental-based) (Fuchs, Fuchs, \& Hamlett, 1989a) and evaluation method (e.g., 3-day decision rule) (Fuchs, 1989).

Using CBM data to make progress monitoring and instructional effectiveness decisions has been shown to affect teachers' instructional planning and teaching. Teachers who received CBM data and qualitative feedback regarding student performance wrote more specific instructional plans (Fuchs, Fuchs, \& Hamlett; 1989a; Fuchs, Fuchs, Hamlett \& Stecker, 1990). In addition, teachers also increased their accuracy with identification of phonetic spelling errors (Fuchs, Allinder, Hamlett, \& Fuchs, 1990).

The implications of this research are encouraging not only in terms of instructional planning, but also but with regard to changes in teaching. Teachers using CBM have been found to make more instructional changes in students' pro- 
grams (e.g., Fuchs, Deno, \& Mirkin, 1984; Fuchs, Fuchs, Hamlett, \& Allinder, 1991b), which may be one of the variables associated with greater student achievement gains. The effect of progress monitoring on the structure of instruction also has been explored. Variables examined included instructional grouping, teacher-directed learning, active academic responding, and prompting (Deno, King, Skiba, Sevcik, \& Wesson, 1983). Teachers who used CBM monitoring procedures demonstrated increased structure in instructional delivery (Fuchs, Deno, \& Mirkin, 1984).

Teacher attitudes regarding student progress and instructional programs also have changed when utilizing CBM progress monitoring procedures. Teachers were more realistic about student progress (Fuchs, Deno, \& Mirkin, 1984) and more open to trying new interventions when a student was not making adequate progress (Fuchs, Deno, \& Mirkin, 1984; Marston \& Magnusson, 1988).

\section{Problem Solution Research Outcomes}

Research on Problem Solution decisions for all assessment practices remains limited. Research on the use of CBM to make this decision is increasing and can be divided into two broad areas: (a) effects on percentages of students exited from special education, and (b) preliminary research on identifying potential candidates for reintegration into general education. Significant increases in special education exit rates have been observed when data relevant to performance in general education curriculum are used in decision making. Marston and Magnusson (1988) reported an increase in the percentage of students exited yearly from special education resource rooms to $20 \%$ from $4 \%$.

Preliminary research on using CBM to identify potential candidates for reintegration shows promise. Shinn, Habedank, Rodden-Nord, and Knutson (1991) examined the percentage of special education students served in resource rooms with an IEP objective in reading who read gradelevel curricular materials in the range of low reading group general education students from their grade placement. The outcomes estimated that approximately $40 \%$ of the special education students read as well as or better than at least one of the low reading group students. These data suggest that these special education students should be considered for return to general education for reading instruction. RoddenNord, Shinn, and Good (in press) researched the effects of these kinds of CBM data on general education teachers' attitudes about reintegrating special education students back into their classrooms for reading instruction. When provided with CBM data indicative of reading skills commensurate with low reading group students, general education teachers' attitudes about reintegration changed positively and sig- nificantly. Teachers reported that they were very willing to reintegrate the special education student.

\section{CONCLUSION}

CBM meets the criteria proposed by Reschly, Kicklighter, and McKee (1988c) for a useful assessment system, that the data collected for special education eligibility be linked to intervention planning and evaluation. CBM typically is used not as a series of tests added to an educator's testing "armament." Instead, it is to be used within a problem-solving model. Using CBM in this manner has a number of positive demonstrated outcomes for each of the five steps of the model proposed here. Most important, students' achievement is affected. When educators write data-based long-term goals and adjust their interventions as a result of students' rates of progress, significant and meaningful changes in student outcomes are observed. Given the legal requirement for evaluation of progress toward annual goals, the field of special education's documented lack of improvement in this area, and the strong potential for changes in student outcomes upon implementation, special education systems should place a high priority on training and implementating of CBM and problem-solving decision-making strategies.

Development of this paper was supported by grant no. 8029D80051-91 from the U.S. Department of Education, Special Education Programs, to provide leadership training in curriculum-based assessment. The views expressed within this paper are not necessarily those of the U.S. DOE.

\section{REFERENCES}

Algozzine, B., Christenson, S., \& Ysseldyke, J. (1982). Probabilities associated with the referral to placement process. Teacher Education \& Special Education, 5, 19-23.

Allen, D. (1989). Periodic and annual reviews and decisions to terminate special education services. In M. R. Shinn (Ed.), Curriculum-based measurement: Assessing special children (pp. 184-203). New York: Guilford.

Bateman, B., \& Herr, C. (1981). Law and special education. In J. Kauffman \& D. Hallahan (Eds.), Handbook of special education (pp. 330-360). Englewood Cliffs, NJ: Prentice Hall.

Bentz, J., Shinn, M., \& Gleason, M. M. (1990). Training general education pupils to monitor reading using curriculum-based measurement procedures. School Psychology Review, 19(1), 23-32.

Bersoff, D. (1973). Silk purses into sow's ears. American Psychologist, 10, 892-899.

Blankenship, C. (1985). Using curriculum-based assessment data to make instructional decisions. Exceptional Children, 52, 233-238.

Canter, A. (1991). Effective psychological services for all students: A databased model of service delivery. In G. Stoner, M. R. Shinn, \& H. M. Walker (Eds.), Interventions for achievement and behavior problems (pp. 49-78). Silver Spring, MD: National Association of School Psychologists.

Deno, S. L. (1985). Curriculum-based measurement: The emerging alternative. Exceptional Children, 52, 219-232.

Deno, S. L. (1986). Formative evaluation of individual student programs: A new role for school psychologists. School Psychology Review, 15, 358-374. 
Deno, S. L. (1989). Curriculum-based measurement and alternative special education services: A fundamental and direct relationship. In M. R. Shinn (Ed.), Curriculum-based measurement: Assessing special children (pp. 1-17). New York: Guilford.

Deno, S. L. (1990). Individual differences and individual difference: The essential difference of special education. Journal of Special Education, 24(2), 160-173.

Deno, S. L., King, R., Skiba, R., Sevcik, B., \& Wesson, C. (1983). The structure of instruction rating scale (SIRS): Development and technical characteristics (Research Rep. No. 107). Minneapolis: University of Minnesota Institute for Research on Learning Disabilities.

Deno, S. L., Marston, D., \& Mirkin, P. (1982). Valid measurement procedures for continuous evaluation of written expression. Exceptional Children, 483, 68-371.

Deno, S. L., Marston, D., Mirkin, P. K., Lowry, L., Sindelar, P., \& Jenkins, J. (1982). The use of standard tasks to measure achievement in reading, spelling, and written expression: A normative and developmental study. Minneapolis: University of Minnesota Institute for Research on Learning Disabilities.

Deno, S. L., Mirkin, P., \& Chiang, B. (1982). Identifying valid measures of reading. Exceptional Children, 49, 36-45.

Education for All Handicapped Children Act of 1975 (PL 94-142, 29 Nov. 1975) United States Statutes at Large, 79, pp. 27-52.

Erez, M. (1977). Feedback: A necessary condition for the goal setting-performance relationship. Journal of Applied Psychology, 62, 624-627.

Fuchs, L. S. (1986). Effects of teacher training procedures on data-based instructional management implementation. (Unpublished manuscript available from L. S. Fuchs, Box 328, Peabody College, Vanderbilt University, Nashville, TN 37203).

Fuchs, L. S. (1988). Effects of computer-managed instruction on teacher's implementation of systematic monitoring programs and student achievement. Journal of Educational Research, 81, 294-304.

Fuchs, L. S. (1989). Evaluating solutions: Monitoring progress and revising intervention plans. In M. R. Shinn (Ed.), Curriculum-based measurement: Assessing special children (pp. 155-183). New York: Guilford.

Fuchs, L. S. (in press). Enhancing instructional programming and student achievement with curriculum-based measurement. In J. Kramer (Ed.), Curriculum-based assessment: Examining old problems, evaluating new solutions. Hillsdale, $\mathrm{NJ}$ : Erlbaum.

Fuchs, L. S., Allinder, R. M., Hamlett, C. L., \& Fuchs, D. (1990). An analysis of spelling curricula and teachers' skills in identifying error types. Remedial \& Special Education, 11(1), 42-51.

Fuchs, L. S., Butterworth, J. R., \& Fuchs, D. (1989). Effects of ongoing curriculum-based measurement on student awareness of goals and progress. Education \& Treatment of Children, 12(1), 63-72.

Fuchs, L. S., \& Deno, S. L. (1991). Paradigmatic distinctions between instructionally relevant measurement models. Exceptional Children, 57(6), 488-500.

Fuchs, L. S., Deno, S. L., \& Mirkin, P. (1984). The effects of frequent curriculum-based measurement and evaluation on pedagogy, student achievement and student awareness of learning. American Educational Research Journal, 21, 449-460.

Fuchs, L. S., \& Fuchs, D. (1986a). Curriculum-based assessment of progress towards long-and short-term goals. Journal of Special Education, 20, 69-82.

Fuchs, L. S., \& Fuchs, D. (1986b). Effects of systematic formative evaluation on student achievement: A meta-analysis. Exceptional Children, 53, 199-208.

Fuchs, L. S., \& Fuchs, D. (1987a). Effects of curriculum-based measurement procedures in spelling and math. (Unpublished manuscript available from L. S. Fuchs, Box 328, Peabody College, Vanderbilt University, Nashville, TN 37203).

Fuchs, L. S., \& Fuchs, D. (1987b). The relation between methods of graphing student performance data and achievement: A meta-analysis. Journal of Special Education Technology, 8, 5-13.

Fuchs, L. S., Fuchs, D., \& Hamlett, C. L. (1989a). Computers and curriculum-based measurement: Effects of teacher feedback systems. School Psychology Review, 18, 112-125.
Fuchs, L. S., Fuchs, D., \& Hamlett, C. (1989b). Effects of alternative goal structures within curriculum-based measurement. Exceptional Children, 55, 429-438.

Fuchs, L. S., Fuchs, D., \& Hamlett, C. L. (1989c). Effects of instrumental use of curriculum-based measurement to enhance instructional programs. Remedial \& Special Education, 10(2), 43-52.

Fuchs, L. S., Fuchs, D., \& Hamlett, C. L. (1989d). Monitoring reading growth using student recalls: Effects of two teacher feedback systems. Journal of Educational Research, 83(2), 103-110.

Fuchs, L. S., Fuchs, D., Hamlett, C. L., \& Allinder, R. M. (1991a). The contribution of skills analysis to curriculum-based measurement in spelling. Exceptional Children, 57(5), 443-452.

Fuchs, L. S., Fuchs, D., Hamlett, C. L., \& Allinder, R. M. (1991b). Effects of expert system advice within curriculum-based measurement on teacher planning and student achievement in spelling. School Psychology Review, 20(1), 49-66.

Fuchs, L. S., Fuchs, D., Hamlett, C. L., \& Hasselbring, T. S. (1987). Using computers with curriculum-based progress monitoring: Effects on teacher efficiency and satisfaction. Journal of Educational Technology, 8, 14-27.

Fuchs, L. S., Fuchs, D., Hamlett, C. L., \& Stecker, P. M. (1990). The role of skills analysis in curriculum-based measurement in math. School Psychology Review, 19(1), 6-22.

Fuchs, L. S., Fuchs, D., \& Maxwell, L. (1988). The validity of informal reading comprehension measures. Remedial \& Special Education, 9, 20-28.

Fuchs, L. S., Hamlett, C. L., \& Fuchs, D. (1990). Monitoring basic skills progress [Computer program]. Austin, TX: PRO-ED.

Fuchs, L. S., Hamlett, C. L., Fuchs, D., Stecker, P. M., \& Ferguson, C. (1988). Conducting curriculum-based measurement with computerized data collection: Effects on efficiency and teacher satisfaction. Journal of Special Education Technology, 9(2), 73-86.

Fuchs, L. S., \& Shinn, M. R. (1989). Writing CBM IEP objectives. In M. R. Shinn (Ed.), Curriculum-based measurement: Assessing special children (pp. 132-154). New York: Guilford.

Gerber, M., \& Semmel, M. (1984). Teachers as imperfect test: Reconceptualizing the referral process. Educational Psychologist, 19, 137-148.

Germann, G., \& Tindal, G. (1985). An application of curriculum based assessment: The use of direct and repeated measurement. Exceptional Children, 52, 244-265.

Gickling, E., \& Thompson, V. (1985). A personal view of curriculum-based assessment. Exceptional Children, 52, 153-165.

Good, R. H., \& Shinn, M. R. (1990). Forecasting accuracy of slope estimates for reading curriculum-based measurement: Empirical evidence. Behavioral Assessment, 12, 179-193.

Heller, K. A., Holtzman, W., \& Messick, S. (1982). Placing children in special education: A strategy for equity. Washington, DC: National Academy Press.

Howell, K. W., \& Morehead, M. K. (1987). Curriculum-based evaluation for special and remedial education. Columbus, $\mathrm{OH}$ : Merrill.

Kavale, K. A., \& Forness, S. R. (1987). Substance over style: Assessing the efficacy of modality testing and teaching. Exceptional Children, 54(3), 228-239.

Knutson, N. (1990). Teaching low-performing students to monitor the reading progress of their cross-age peers. Unpublished doctoral dissertation, University of Oregon, Eugene.

Marston, D. (1989). Curriculum-based measurement: What is it and why do it? In M. R. Shinn (Ed.), Curriculum-based measurement: Assessing special children (pp. 18-78). New York: Guilford Press.

Marston, D., Fuchs, L. S., \& Deno, S. L. (1986). A comparison of standardized achievement tests and direct measurement techniques in measuring student progress. Diagnostique, 11, 77-90.

Marston, D., Lowry, L., Deno, S. L., \& Mirkin, P. K. (1981). An analysis of learning trends in simple measures of reading, spelling, and written expression: A longitudinal study (Research Rep. No. 49). Minneapolis: University of Minnesota Institute for Research on Learning Disabilities.

Marston, D., \& Magnusson, D. (1985). Implementing curriculum-based measurement in special and regular education settings. Exceptional Children, 52, 266-276. 
Marston, D., \& Magnusson, D. (1988). Curriculum-based assessment: District-level implementation. In J. Graden, J. Zins, \& M. Curtis (Eds.), Alternative educational delivery systems: Enhancing instructional options for all students (pp. 137-172). Washington, DC: National Association of School Psychologists.

Reschly, D. J., Genshaft, J., \& Binder, M. S. (1987). The 1986 NASP survey: Comparison of practitioners, NASP leadership, and university faculty on key issues. Washington, DC: National Association of School Psychologists.

Reschly, D. J., Kicklighter, R., \& McKee, P. (1988a). Recent placement litigation, Part I, Regular education grouping: Comparison of Marshall (1984, 1985) and Hobson $(1967,1969)$. School Psychology Review, 17, 9-21.

Reschly, D. J., Kicklighter, R., \& McKee, P. (1988b). Recent placement litigation, Part II, Minority EMR overrepresentation: Comparison of Larry P. $(1979,1984,1986)$ with Marshall $(1984,1985)$ and S-1 (1986). School Psychology Review, 17, 22-49.

Reschly, D. J., Kicklighter, R., \& McKee, P. (1988c). Recent placement litigation, Part III, Analysis of differences in Larry P., Marshall, and S-1 and implications for future practices. School Psychology Review, 17, 39-50.

Rodden-Nord, K., Shinn, M. R., \& Good, R. H. (in press). Effects of classroom performance data on general education teachers' attitudes towards reintegrating students with learning disabilities. School Psychology Review.

Shinn, M. R. (1988). Development of curriculum-based local norms for use in special education decision making. School Psychology Review, 17, 61-80.

Shinn, M. R. (Ed.). (1989a). Curriculum-based measurement: Assessing special children. New York: Guilford.

Shinn, M. R. (1989b). Identifying and defining academic problems: CBM screening and eligibility procedures. In M. R. Shinn (Ed.), Curriculum-based measurement: Assessing special children (pp. 90-129). New York: Guilford.

Shinn, M. R., \& Good, R. H. (in press). CBA: An assessment of its current status and a prognosis for its future. In J. Kramer (Ed.), Curriculumbased assessment: Examining old problems, evaluating new solutions. Hillsdale, NJ: Erlbaum.

Shinn, M.R., Habedank, L., Rodden-Nord, K., \& Knutson, N. (1991). Using curriculum-based measurement to identify potential candidates for reintegration into general education. (Unpublished manuscript available from M. R. Shinn, School Psychology Program, College of Education, University of Oregon, Eugene, OR 97403)

Shinn, M. R., \& Marston, D. (1985). Differentiating mildly handicapped, low-achieving and regular education students: A curriculum-based approach. Remedial \& Special Education, 6, 31-45.
Shinn, M. R., Nolet, V., \& Knutson, N. (1990). Best practices in curriculum-based measurement. In A. Thomas \& J. Grimes (Eds.), Best practices in school psychology (pp. 287-308). Washington DC: National Association of School Psychologists.

Shinn, M. R., Rosenfield, S., \& Knutson, N. (1989). Curriculum-based assessment: A comparison and integration of models. School Psychology Review.

Shinn, M. R., Tindal, G., \& Spira, D. (1987). Special education referrals as an index of teacher tolerance: Are teachers imperfect tests? Exceptional Children, 54, 32-40.

Shinn, M., Tindal, G., Spira, D., \& Marston, D. (1987). Practice of learning disabilities as social policy. Learning Disabilities Quarterly, 10(1), 17-28.

Shinn, M. R., Ysseldyke, J., Deno, S. L., \& Tindal, G. (1986). A comparison of differences between students labeled learning disabled and low achieving on measures of classroom performance. Journal of Learning Disabilities, 19, 545-552.

Smith, S. W. (1990). Individualized educational programs (IEPs) in special education: From intent to acquiescence. Exceptional Children, 57(1), 6-14.

Tindal, G., Fuchs, L. S., Christenson, S., Mirkin, P. K., \& Deno, S. L. (1981). The relationship between student achievement and teacher assessment of short- or long-term goals (Research Rep. No. 61). Minneapolis: University of Minnesota, Institute for Research on Learning Disabilities. (ERIC Document Reproduction Service No. Ed 218 846).

Tucker, J. (1985). Curriculum-based assessment: An introduction. Exceptional Children, 52, 199-204.

Wesson, C. (1987). Increasing efficiency. Teaching Exceptional Children, 20, 46-47.

Wesson, C., Fuchs, L., Tindal, G., Mirkin, P., \& Deno, S. L. (1986). Facilitating the efficiency of ongoing curriculum-based measurement. Teacher Education \& Special Education, 9, 166-172.

Wesson, C. L., King, R. P., \& Deno, S. L. (1984). Direct and repeated measurement of student performance: If it's good for us, why don't we do it? Learning Disability Quarterly, 7, 45-48.

White, O. R. (1974). Evaluating educational process Unpublished manuscript, University of Washington, Child Developmental and Mental Retardation Center, Experimental Education Unit, Seattle.

White, O. R., \& Haring, N. G. (1980). Exceptional teaching (2nd ed.). Columbus, $\mathrm{OH}$ : Merrill.

Ysseldyke, J. E., Algozzine, B., Shinn, M. R., \& McGue, M. (1982). Similarities and differences between low achievers and students labeled learning disabled. Journal of Special Education, 16, 73-85.

Ysseldyke, J. E., \& Thurlow, M. L. (1984). Assessment practices in special education: Adequacy and appropriateness. Educational Psychologist, $9,123-136$.

\section{PERMISSIONS AND COPYRIGHT}

All rights are reserved. No part of this publication may be reproduced, photocopied, faxed, stored in a retrieval system, or transmitted, in any form or by any means, electronic, mechanical, recording or otherwise, without the prior written permission of the publisher.
Back issues are available for sale. Reproduction requires permission and payment of fees. It is illegal and a violation of Federal copyright law to reproduce this publication without permission. Direct all inquiries to the permissions editor. 